\title{
A Comparative Investigation of Political Thoughts of Davari and Soroush Regarding the West
}

\author{
Hossein Roohani \\ Ph.D. student, Department of Political Science, University of Isfahan \\ hosseinroohani@gmail.com \\ Alireza Aghahosseini \\ Assistant Professor, Department of Political Science, University of Isfahan \\ Alireza.aghahosseini@gmail.com \\ Javad Emamjomezade \\ Associate Professor, Department of Political Science, University of Isfahan \\ JavadEmam@yahoo.com
}

Doi:10.5901/mjss.2014.v5n7p555

\begin{abstract}
After the victory of the Islamic Revolution of Iran, scholars and thinkers encountered new scientific conditions, modern political ideas and newly established time and ground, and each, responding to these new upheavals which was the governance and fulfilment of Islamic commandments in all political, social, cultural and economic fields, presented ideas appropriate to their thought constellation. Reza Davari as a Fardidian thinker, following the ideas of the famous German philosopher, Martin Heidegger, criticizes the West philosophically and phenomenologically and knows the only redemptive path for Iranians as leaving the West as an integrated whole and criticizes modernity in a severe way. Contrary to this uncompromising approach to the West, another approach, particularly in the second and third decades of the Islamic Revolution gradually appeared which practiced sympathetic approaches to the West and Abdul Karim Soroush as the forerunner of this approach, tried to pave that path for establishing modernism by an epistemological reading of religion. In the present article, it has been tried to discuss and compare the ideas and thoughts of Davari and Soroush to the West.
\end{abstract}

Keywords: Davari, Soroush, subjectivism, the West

\section{Introduction}

Undoubtedly, one of the conflicting concepts in the literature of the thought constellation of contemporary Iran is the concept of the West which every intellectual movement has spoken of it based on its own intellectual requirements. With little tolerance, one can discuss that the point of departure of Iranians' encountering the West refers to the Constitutional Revolution Period when some of the thinkers and clergies of that historical period started to think how to practice a strategy for the West. A group of intellectuals was interested with the West and knew the solution in accepting indubitably the culture and civilization the West and started to oppose the tradition and primarily the religion. The opposite point of this movement of advocating the West, there was a movement which rejected the West as a hegemonic and irreligion civilization and tried severely to oppose it. Also, there was another group who wanted to make a bridge between tradition and modernity and through this constructed a third way whose result was interaction between the West and the East civilizations. Since the ancient, this conflict between Westernizers and those who oppose the West has been common in the intellectual constellation of Iran and the conflict between these two approaches can still be observed whether in intellectual arena whether in political, social and cultural arenas. The advent of Iran's Islamic Revolution and the formation of the Islamic system resulted in this issue that the anti-west approach in the intellectual constellation of Iran survived and could present its own ideas in the field of evidence and proof through the dominant discursive environment in the first anti-West decade of the Islamic revolution. Reza Davari Ardakani is among those intellectuals who influenced by his master Ahmad Fardid, tried to form a discourse through writing books and articles which the constructive elements of this discourse can be identified in the light of indices such as opposition to the West as an integrated whole and leaving 
subjectivism and exploiting a Heideggerian approach in criticizing modernity. Davari, influenced by the context of his time which was an anti-West environment and also inspired by the atmosphere created by the Islamic Revolution, tried to stand against westernizers and religious intellectuals. He, influenced by Martin Heidegger's ideas and also his master Fardid, claimed that the West is not like a chair which is placed in a place and can be pointed. The West is a kind of look which human beings have to the world and the basic problem of the West is subjectivism and humanism which by the collapse of the Church, this humanism reaches its peak. Descartes as the forerunner of subjectivism, locates subject as axis and center of the universe. To Davari who is influenced by the phenomenological method of Heidegger, the West is an unavoidable event in human history which should be accepted, but this does not mean that one cannot come out of westernization. He emphasizes that one should not surrender to the calamity of the time, but one should think of this event-the West- and not imitate it. Davari knows the Islamic revolution as the advent of the sign of the end of western history and the beginning of another age in the shadow of God's mercy and tries to present a new plan which paves the path along passing westernization and subjectivism. Simultaneous to shaping the ideas of intellectuals such as Davari and Fardid who wanted to present some strategies for passing from westernization with the advent of the Islamic revolution, another approach was about to be given birth and developed in Iran which after the end of Iran-Iraq war and influenced by the environment created due to the collapse of the Soviet Union, obviously and blatantly showed itself in the intellectual and thought filed of Iran. One of the most important theoreticians of this approach, later known as the Popperian approach, is Abdol Karim Soroush who, with ups and downs in his intellectual constellation, practically welcomed modernity and criticized tradition by standing on the peak of modernity. Soroush in early revolution, as he did not speak of his enthusiasm to modernity and in some cases he criticized modernity and technology, but gradually shaped a combination of modernist, post-modernist and mystical ideas particularly during Reconstruction and Reform influenced by the post-modernist environment in the world. The result of this combination of thoughts is writing and publishing different and multiple works which are still the arena of conflict among thinkers and intellectuals. Soroush, opposing the ideas of those who reject the West as an integrated whole, influenced by liberalism, applies his secularist consideration of the religion and tries to modernize the religion and criticize ideological and jurisprudential Islam, and consequently pave that path for the conditions and requirements for reinforcing the root of the tree of modernity in the soul of Iran. However Soroush calls himself religious intellectual, he is about to thin religion; by religion he means is ethics and spirituality which is seriously contrary to the definition of religion as tradition, decrees and commandments. Inspired by the ideas of scholars such as Popper, Quine and Gadamer, practically and really stands against antimodernist scholars such as Fardid and Davari and with a positive and sympathetic approach to the western civilization, makes an intellectual conflict official which is known as the conflict between two westernization and anti-West approaches. A hypothesis presented to be tested is that the different approach and interpretation of the West is the main reason of Soroush and Davari regarding the concept of the West.

\section{The Quiddity of the West from Reza Davari's Viewpoint}

Representing the West is considered as one of the theoretical basics of Davari. Davari is about to organize his own intellectual system through representing otherness of what can be known as modernity and in general the West. Davari's works are filled with presenting absolute otherness of the West; he through this representation tries to represent as a tradition and integrated whole (Pedram, 2004: 78). The first point in Davari's Occidentalism refers to this important issue that he considers the West more than a civilization and a particular geography and he considers it as a relevance and relationship with the existence, universe and human. Regarding this discussion, he writes "the West is not fixed Platonic ideas, the West is a mode of view which humans have towards the Universe" (Davari, 1988: 85). Davari knows those who do not believe in the unity of the west as disbelievers in intellect, advocates of the status quo of the world and the apologists of egoism and arrogance. Accordingly he writes that "some of the authors of contemporary philosophy who merely have the name of philosophy with them and repeatedly deny intellect, apparently to defend the status quo of the world and in order that the unity of the West be untouched, rejects the project if the West's nature and deny its unity in order to consider the ugly results of justified arrogance and conceitedness as unrelated to the West and claim that what is called the West is a collection of goddess and badness, beauties and ugliness, which goodness should be selected and badness should be left. With what criterion does one select goodness and leave badness? The answer is the criterion of reason" (Davari, 1988: 74). By these words, Davari rejects the West as an integrated whole because in his view, denying the nature of the West results in ignoring the nature of the West and considering the apparent conflicts between Marxism and Liberalism as serious, while the origin and problem of both is one thing (Nasri, 2011: 273). Among the most important characteristics of the West is the new consideration of the world which human being is the criterion and scale of measuring everything, and this issue, in Davari's view, does not mean that human beings ignore the reason, but in the 
new system of the West, the reason ignores the guidance and rejects the absolute reason (Davari, 1988: 84). In Davari's view, the west is a world which in historical age has been created with the mode of thought and by opening a horizon in which human beings have gradually attained centrality of the creatures (Davari, 1996: 117). Davari knows the new age as the age of Reign of Man and emphasizes the components such as "the age of falling heavenly thought and nostalgia for human beings" and "human being's loss in a meaningless world" (Davari, 1998: 32). The main concern for Davari is to bare the nature of the collapse of the West, particularly modernity and find a path to exit the comprehensive reign of the West. Davari defines the West using philosophy and metaphysics. He sees philosophical thought as the basis of modernity and traces its origin in Plato's and Aristotle's ideas (Pedram, 2004: 80). He analyzes that "when thought appeared in the form of philosophy, philosophy had had its own technological science, it means that from the very beginning, it should have been in a path of scientific form. If in the new age, the desire of philosophy's being scientific in the form of different philosophies appeared, this desire is briefly has been presented in the principles and basics of all philosophies (Davari, 1984: 104). Davari traces the origin of modernity in 18 ${ }^{\text {th }}$ century and Enlightenment which "philosophers such as Descartes by presenting proposition of "cogito ergo sum", raise officially and obviously the flag of subjectivism and in the new history of the West, i.e. modernity, another human being appeared who was the legislator itself and according to the requirements and capabilities which was present in each ethnic group and every group, legislates laws. It is obvious that legislating such law is not based on flightiness; however, when human beings legislate laws by calculating capabilities and considering requirements and according to it investigate the world, give all things the human shape and in politics, judgment, science and teachings and everywhere the human power appears (Davari, 1980: 18). In addition, Davari discuss this issue that "in fact the West should not be divided into good and bad and beautiful and ugly. The West is not the sum of atoms and elements which are located close to each other, but it is as an integrated whole whose components cannot be entered in any new integration" (Davari, 1984: 22). Therefore, to Davari, the main and root conflict between western and eastern identity is due to not being additive of their humanisms. Because the West and the East are representative of two kinds of existence, humanism is not merely a kind of philosophy, but is a kind of being based on which the human concept appears in the form of the West's unitary issue (Davari, 1984: 59). According to Davari, because after the invasion of the West and modernity, the order of Eastern human existence has been cluttered, identity crisis and loss crisis appear which we consider it as duality crisis. Duality crisis is there where human is standing between the worlds, he is neither here nor there or he is both here and there (Davari, 1996: 144). In other words, the crisis of the easterners is related to the crisis of not having history. Because we have neither real connections to our own past nor to that of the West, we do not have history (Davari, 1984: 5). Davari states these words that "new history of the West was not such that an ethnic group voluntarily be interested in it and another ethnic group reject it, but all people of the world should enter this history. Then, regarding the West's forcible expansion I have stated that true journey in the land of the West is better than exhaustion and frustration" (Davari, 1978: 10). Davari in this statement speaks of forcibility and inevitability of the western civilization and that the West is an event and we should ponder in this event to exit the rank of imitation (Davari, 1988: 132). Furthermore, he emphasizes this point that if the West has been able to dominate the world and make the farness and ignorance of the easterners from their own heritages more and more, their main reason is that before the invasion of the West, the foundation of other histories and particularly easterners became loose (Davari, 1996: 10). This Iranian thinker, then states that "undoubtedly, without familiarity with the past and remark about that, the serious connection with the western thought and civilization is not possible. But considering these nonsense habits instead of the past culture and civilization is farness from the past and persistence on it cause that we be far from it, and more than ever it makes us confused and lost" (Davari, 2001: 95). Davari considers the condition of passing subjectivism which is filled with the western civilization, in this point that "the East is not a collection of traditions and rituals of eastern ethnics ... if the reality of our East is these rituals and traditions, orientalists would have found the reality of the East. The East cannot be known by methodology and in general scientific epistemology. The East is neither a geographical region nor a collection of behaviors and rituals of its residents. We cannot approach to the East without confronting the East and the West" (Davari, 1978: 42). This statement of Davari means that although the East apparently is a past which has got the substance of the history of the West, it is in fact the future of the West (Davari, 1978: 59). Although Davari speaks of the defeat and basics of modernity and states that the column of modernity has been broken and unfaithful (Davari, 1991a: 17), he immediately emphasized that "what has been said regarding the results of the fall of the West does not confirm any advantage for us. It should be noted that denying the West does not result in freeing from the force and domination of the western civilization and it may be advantageous for the world filled with possibilities; however, in any world, possibilities and their boundaries are different; the residents of the West are involved with these possibilities which guide their thought and behavior" (Davari, 1999: 8). Completing his ideas regarding the West, Davari writes that "we cannot deny the technological developments and technological sciences, but to reach higher ranks it is necessary that we be free from being too scientific and technical" (Davari, 2000: 49). Davari considers one of the 
requirements and tools needed for passing westernization as familiarity with the West and Post-modernism and writes: "in the present time and condition, one of the ways of the necessity of familiarity with postmodernism is that we can know the West through them. Postmodernism is a preparatory thought. In the preparatory period, referring to the East and returning to the words of the instructors of heavenly thought lead us to the light of the future world" (Davari, 1999: 40). This thinker critic of the West takes this age as the age of limbo of postmodernism, it means the ages that insecurity has been penetrated in the basics of modernity and the West is in a crisis (Davari, 1988: 24). Although Davari in most of his works rejects the approach to select the West, he emphasizes this point that "from these statements and words it is never used that we should deny and ignore all things that in the new age called science, industry and development appear. My issue is that we should not surrender the force of the time" (Davari, 1988: 132).

\section{The Quiddity of the West from Soroush's Viewpoint}

Soroush's viewpoint regarding the West is not unitary and stable. In the early Islamic revolution, he had an aggressive approach to the West and saw the western thought as a whole and stated: "they claimed that if one can take the science of the westerners, he cannot take their morality. It is true, but in practice, we saw that this not so easy. Their issues is not separable in this way. They (westerners) are complicated systems which one should be so naïve to imagine that you yourself did not understand this and confuses them; however, we understood it well. We put aside the bad parts of it and took the good ones. These are impossible" (Soroush, 1979: 13-14). Soroush also attacks the technology of the West: "this illusion that industrialization results in being more powerful and needless and convenient is absolutely wrong. Technique does not lessen needs, but it increases them and managing and controlling a collection and simple society is not more complicated than a complicated one, but is so easier" (Soroush, 1987: 312). He adds: "regarding the power which is the child of industry, we should discuss more. The point is that technique is the last need and need is frustrating, consequently it is not empowering, but humiliating" (Soroush, 1987: 314). that Soroush in these clear sentences written in early Revolution and influenced by the anti-West discourse environment of the day attacks being too technical and states that our revolutionary society has no business with industry and how one can manage this severe upheaval which has feared its creators (Soroush, 1987: 2-3). This critical viewpoint of Soroush regarding the West and technology reflected in early Islamic Revolution, after the year 1988 transformed fundamentally and this time, Soroush challenges the anti-West thoughts of thinkers such as Davari and Fardid and states: "they think that as soon as they claim-albeit without any reason- that the relationship of westerners with the nature or the existence is changed and humanity is about to dominate the Universe and human beings and is becoming far from God and is surrounded by the West's lust and spirituality, they have the key of all problems and the analysis of all approvals and make themselves and others filled with other's interpretation and explication and by this unproved claim clarify to all people the destiny of philosophy and science and technology and literature and art of westerners" (Soroush, 1994: 246). Soroush, criticizing those who deny the West as an integrated whole, refers to the complicated concept of the West among Iranians and by presenting the question of the quiddity of the West, recalls the complicatedness of this concept in such a way that "is the West a particular set of thoughts or a mode of the existence of humanity or a method of living and managing, or the very sensuality or a mode of history realization or the invasion of technology and the fall of tradition or US foreign policy or other things?" (Soroush, 1996: 9). Then he answers this question as such: "the correct path of knowing the West is that we separate the verdict of motivation from motivation and do not replace credit unity by true unity and do not imagine that returning affairs to their basics and natures will make us needless of everything" (Soroush, 1996: 241). Because Soroush does not consider any single real and genuine unity for the West, he easily can analyze it and take its desired elements and leave its undesired ones and select those elements from the West which he considers as right. Because in Soroush's view, "no right is strange for another one. Rights are all relatives and goods and purity are all friends. Lights are all from the same nature and beauties are all from the same origin" (Soroush, 1987: 249). Among the pillars of modernity, Soroush indicates a particular interest to the modern science and states that:" universality and cosmopolitanism as well as barrier breaking is such that comply with all and do not remain in the domain of anybody" (Soroush, 1994: 5). He knows the scientific knowledge successful in changing the world and concludes that the future path should be taken by the modern science (Soroush, 1996: 1-8). Soroush by presenting this issue that epistemic unreligious knowledge of scholars is in continuous development and evolution, claims that understanding religion is developing and religious knowledge like other kinds of knowledge is the result of human search and thought and is always a combination of philosophies, rights and wrongs (Soroush, 1992: 115-119). Soroush's emphasis on prophecy of religious knowledge and its development due to the development other human knowledge can provide a basis for shaping a humanistic image of religion (Pedram, 2004: 119). In his thought constellation, Soroush considers a significant status for western reason and emphasizes modernity. He writes that "the critical status of religious intellectuals is modernity. In other words, the explorations conducted in the 
modern era, including new sciences, new philosophy, new politics and art and ethics all give the religious intellectual a critical status, it means that the new reason gives the religion a scale and eyeglasses to look through the tradition and religious power and scale them" (Soroush, 1383: 7). He even in explicating a religious democratic government which he himself trust, emphasizes that "religious government should start with human rights, judgment and limiting power which all are extra-religious issues and then it should modify its religious understanding by them" (Soroush, 1997: 302). Therefore, to Soroush, religious government is that whose laws are determined by a non-religious self-founded reason (Soroush, 2000: 51). Furthermore, Soroush is interested in liberalism and by reciting a famous statement of Kant telling "Have the courage to know" praises liberalism of the west and identifies constructive elements of liberalist discourse in the light of indices such as considering understanding the truth as non-exclusive, free from sanctities, considering human fallibility, the existence of natural right and individualism and tolerance and moderation (Soroush: 2004: 13). Accordingly, it can be concluded that Soroush does not deny the West as an integrated whole and on the contrary, in many of his works except some of his works, not only does not rejects the west, but also he praises modernity and consider defending religion as rightful as far as it does not have any contradiction to modernity and elements related to it.

\section{Comparative Investigation of Davari's and Soroush's Viewpoints Regarding the West}

One of the most important and fundamental intellectual conflicts between Davari and Soroush is that Davari rejects the West as an integrated whole and warns that the western civilization is not a combination of separated components some of which can be selected and some can be left. If an ethnic group want to imitate the west based on an incorrect image and does not consider the intellectual basics of this civilization and does not know what the basis of magnificent ground of that founder is and how it is extended, it will be confused and disorganized and consequently it drops behind (Davari, 2001: 95). Meanwhile, Soroush presents this issue that there are different decrees for different aspects of the West and accordingly he offers the analysis and selection and writes that "our statement is that the western system is neither unitary nor unique ... one should select fearlessly" (Soroush, 1987). He speaks of religious pluralism, separation of religion and religious knowledge and the linkage of religious knowledge with other human knowledge and states that "firstly, there is no understanding of religion which is not based on the knowledge and understandings outside the religion. Secondly, if the external understandings change, the understanding of the religion will change ... thirdly, the understandings outside the religion will change" (Soroush, 1994: 157).

This views held by Soroush regarding separation of the religion from religious knowledge and interpretability of religion is in line with subjectivism and this is the opposite point of Davari's views because Davari rejects subjectivism and criticizes the West for neglecting ontology and being interested in epistemology. Davari cast criticism upon new sciences because of making dominant materialism and rationalism and asks why the West has not brought about religious philosophers in recent centuries (Davari, 1990: 35). Davari presents this statement which the only solution for the west reached to the end is that it should give up collective and individual arrogance and humanism, leave skepticism, cut the carious tree of modernity, give up subjectivism and reject the West as an integrated whole (Davari, 1990: 36). Responding the rejection of the west as an integrated whole proposed by Davari, Soroush states that Davari's philosophical hypothesis regarding the West as an integrated whole is a Hegelian reformulation which leaves no place for constructive dialogue. He criticizes Davari's propositions from one perspective that people should accept the West totally or reject it completely (Soroush, 1987: 231). Soroush who paves the path for interaction of religious and nonreligious knowledge by the theory of Theoretical Contraction and Expansion of Shari'a, states that Iranians are bound to and heir of three national, religious and western cultures and should try to make a compromise among these three (Soroush, 1990: 11). Although Soroush apparently emphasizes the interaction between extra- and inter-religious knowledge, finally he believes in modernity and requirements related to it and states that "if inter-religious assignments or rights contradict with extra-religious ones, extra-religious ones are prioritized" (Soroush, 2000: 155). Contrary to Soroush, Davari rejects the West and writes about the imposing and importing nature of modernity in Iran and the rest of Islam: "modernity is a tree whose origin can be followed in the West; it covers all over. We lived under the shadow of the rotten branches of this tree for many years and it is still over us. In spite that we seek refuge in Islam, what should we do with this withered branches?" (Davari, 1982: 83). Davari's answer is clear. In his view, not only branches but also the tree of modernity itself should be cut and this work can be possible only by organizing a particular reason, a reason which is distinguished and prioritized to the western one. Davari rejects the western patterns of democracy which are based on the separation of politics from religion as a degenerate issue. Contrary to Soroush who believes in religious pluralism, he is about to organize another type of reason which is based on Guardianship and Prophecy (concepts in Shiite) (Davari, 1982: 85). Davari attacks religious intellectuals such as Soroush who try to interpret religion based on humanism and subjectivism and states that "those who try to serve the religion through modernizing it using ideas and views of western ideologies, 
are hurting religion, science, reason and understanding of humans and they are in the lowest levels of westernization" (Davari, 1986: 228). Davari criticizes the western liberal democracy which those like Popper defend and states that "Popper is a Sophist dependent to intellectualism of $18^{\text {th }}$ century of Europe whose interpretation of freedom is in fact freedom of religion" (Davari, 1986: 12). Davari attacks Popper's positivist interpretation and presents this issue that Popper does not perceive the language of philosophers; therefore, he distorts the ideas of Plato, Aristotle, Hegel and Marx. He also warns this issue that Popper prioritizes falsification over religious intuition by this claim that science deals with what exists and religion deals with what should exist (Davari, 1985: 23-26). Responding the Davari's criticisms of Popper and ideas assigned to him, Soroush accuses Davari to determinism and historicism. To Soroush, Davari's thoughts inspired by Heidegger and Nietzsche is mystical and idealistic thoughts which reduce all things to history and consider no originality for human and human will. Soroush criticizes Hegel for his theoretical philosophy of history and his emphasis on historical determinism and considers such a philosopher as the vindicator Prussian and Heidegger as the advocate of Fascism. In Soroush's view, Hegel's theory of the state and Heidegger's existential phenomenology all are introductions of political and knowledge totalitarianism and tyranny (Soroush, 1980: 3-25). Responding Soroush's views regarding Heidegger who challenges subjectivism, Davari considers Heidegger as the intellectual who could challenges the 2500 year old history of western metaphysics and speak of negligence of the existence. Davari introduces Heidegger as the great wise of our age and the master of future thought (Davari, 1980: 210).

Soroush who has a sympathetic approach to modernity, states that jurisprudence as a human science is based on the nature of interpretation and it is theoretical and because science and philosophy are developing, understanding Shari'ah which is based on sacred texts and tradition, should be transformed. Soroush concludes that because philosophy and natural sciences are always incomplete and are in search of completeness, jurisprudence is incomplete, hence transient and moribund (Soroush, 1992: 50-56). Davari who challenges all philosophical hypotheses of modernity, considers the renewal of the project of Soroush's jurisprudence doom to failure and states that "we are thinking of modernizing religion, universities, traffic, culture and belief, but we do not consider that modernity itself is a belief. Modernity is not a combination of things. In other words, we want to modernize the belief itself. But westerners did not such a work for themselves and now they are doing for us. They did not modernize their belief, but gave up a belief and replace it with another belief called modernity" (Davari, 1991b: 12). He adds: "we should not speak of religion or jurisprudence repeatedly. We should consider that jurisprudence neither revolutionizes nor save the world but it is the agenda of everyday life... we in the age of postmodern are owners of modernity! This is a tragedy. In the age when humanity does not have history, we want to realize a history" (Davari, 1991b: 13). Soroush, contrary to Davari who rejects all schools and ideologies related to modernity because of humanistic and subjectivist approach, shows a great sympathy to the western basics and writes: "liberalism is the result of an epistemological message which knows certainty as a latefound but unfound issue; therefore, calls all fallible human beings to gather around the table of knowledge and give up the arrogance and this means leaving affairs for collective reason and rejecting epistemological, political and religious tyranny" (Soroush, 2001: 8). Meanwhile, Davari is interested in neither socialism nor liberalism and states in this regards that "Islam approves neither capitalism nor socialism" (Davari, 1982: 22). It seems that however Soroush and Davari belong to two different even contradictory intellectual approaches, they share this issue which is the dichotomous view of these two contemporary intellectuals. In Soroush's project, what attracts attentions is the implicit acceptance of modernity and creation of a dichotomy of tradition-modern which in fact is falling in the land of renewal theories. In Davari's intellectual constellation, contrary to that of Soroush, modernity is going to be vanished and any compromise between tradition and modernity is discouraged (Pedram, 2004: 73).

\section{Conclusion}

Undoubtedly, the intellectual conflict between westernizers and anti-West intellectuals since early Constitution has been the arena of thinking and debating among scholars and intellectuals and each intellectual approach has spoken this issue in terms of its intellectual richness. In Iran of after the Islamic Revolution, two intellectual approaches stood against each other. Abdol Karim Soroush as the representative of the religious intellectualism approach with a sympathetic approach with the West tried to criticizes the status of modernity. Soroush selected a selective approach regarding the West and spoke that the West could be divided into good and bad components and create a kind of modernized Islam whose constructive element and components can identified in the light of indices like religious pluralism, religious democratic state and praising modernity and achievements related to it. Undoubtedly, the reason of Soroush's interest to the West and its achievements particularly in the second and third decades of the Revolution was the upheavals which had occurred in the internal and global levels. The collapse of the Soviet Union and the advent of new ideas such as 
Hermeneutics resulted in the fact that religious intellectuals such as Soroush influenced by the environments created due to liberalism and globalization, took a sympathetic approach to the West.

In this arena, Reza Davari Ardakani as one of the forerunners of the approaches critical of the West, influenced by the critical environment of the Islamic Revolution stood against Soroush and stated that modernity is the tree that has originated in the West and is pervasive everywhere. The only way coming out of modernity is that not only its branches but also the tree of modernity itself should be cut. Davari knows postmodernism not as the time of after modernism but its final and critical stage and attacks the western subjectivism. In this line, criticizes those intellectuals who attack tradition. In addition, Davari stands against those like Soroush who are about to modernize the religion and Islam and believes that technology is not an instrument but is a belief and a mode of thinking which passes all human aspects and cannot make a compromise between the West and the East by modernizing Islam and compromising tradition and modernity. For Davari, the West is a forceful issue which has happened and it is inevitable that the only way of passing it is to know the nature of the West and consequently giving up subjectivism. It seems that Soroush, contrary to Davari, takes a positive approach regarding the West and tries to follow the project of rationalizing the religion whose logical results is acceptance of modernity and falling in the land of subjectivism and epistemology, but Davari tries to reject western subjectivism and replace ontology $b$ rejecting the West as an integrated whole and a philosophical and phenomenological approach. It should be noted that in spite of the contradictory approaches of these two Iranian scholars, both use western thinkers for shaping their ideas and views.

\section{References}

Pedram, M. (2004). Religious intellectuals and modernity in Iran after the Islamic Revolution. Tehran: Gam-e-Now publication.

Davari, R. (1978). The status quo of thought in Iran. Tehran: Soroush publication.

Davari, R. (1980). What is philosophy? Tehran: Islamic Association Wisdom and Philosophy.

Davari, R. (1982). Islamic Revolution and the status quo of the world. Tehran: Allameh Tabatabaei Cultural Center publication.

Davari, R. (1984). Introduction to history of our westernization. Tehran: Soroush publication.

Davari, R. (1985). "Some considerations regarding the open society and its enemies". Keyhan-e-farhangi Journal. $2^{\text {nd }}$ year. No.10.

Davari, R. (1986). "Yes to science and freedom, no to hybridization". Keyhan-e-farhangi. $3^{\text {rd }}$ year No. 1.

Davari, R. (1988). Philosophy in crisis. Tehran: Amir Kabir publication.

Davari, R. (1990). "Where is the rendezvous of technique?"Work and development journal. $1^{\text {st }}$ year. No. 1.

Davari, R. (1991a). "Separation in principles and basics of modernity". Editorial of Name-e-farhang journal. No, 23.

Davari, R. (1991b). "Tradition, modernity and postmodernism". Keyhan-e-havaei journal. No. 965.

Davari, R. (1996). Tradition, modernity, postmodernism. A. Ganji (Ed.). Tehran: Serat publication.

Davari, R. (1998). Farabi, the founder of Islamic philosophy. Tehran: Institute for Humanities and cultural studies.

Davari, R. (1999). Culture, reason and freedom. Tehran: Saghi publication.

Davari, R. (2000). Of science. Tehran: Hermes publication.

Davari, R. (2001). Civilization and western thought. Tehran: Saghi publication.

Soroush, A. (1979). "An interview with Dr. Abdol Karim Soroush". Tehran: Muslim Women's Movement.

Soroush, A. (1980). From historicism to Deism. Islamic Student Association of America and Canada.

Soroush, A. (1992). Theoretical Contraction and Expansion of Shari'a. Tehran: Serat publication.

Soroush, A. (1994). Thicker than ideology. Tehran: Serat publication.

Soroush, A. (1996). Disturbed mentality, confused identity. Kian journal. No. 30.

Soroush, A. (1997). Tolerance and Management. Tehran: Serat publication.

Soroush, A. (2000). Rituals of monarchy and religiosity. Tehran: Serat publication.

Soroush, A. (2001). Gods' morality. Tehran: Tarh-e-Now publication.

Soroush, A. (2004). Knowing Secrets intellectuality and religiosity. Tehran: Serat publication.

Soroush, A. (2006). "Tradition of religious intellectuality". Madseseh journal. $2^{\text {nd }}$ year. No. 2.

Nasri, A. (2011). Encountering modernity. Tehran: Elm publication. 